\title{
The impact of post-procedural ureteric stent duration on the outcome of retrograde endopyelotomy for management of failed open pyeloplasty in children: a preliminary report
}

\author{
Mehdi Shirazi $^{1}$, Alireza Aminsharifi*1,2 (D) Faisal Ahmed ${ }^{1,3}$, Alireza Makarem¹, Seyed Alihossein Zahraei ${ }^{4}$, \\ Naeimehossadat Asmaarian ${ }^{5}$
}

Received: 12 Dec 2019

Published: 25 Aug 2020

\section{Abstract}

Background: To evaluate the outcome of retrograde endopyelotomy as a minimally invasive option for management of failed open pyeloplasty in children and assess how the duration of post-procedural stenting may affect the endopyelotomy outcome.

Methods: A total of 15 patients with secondary UPJO (Ureteropelvic junction obstruction) underwent retrograde endopyelotomy. The procedure was done using low-energy monopolar electrocautery hook under direct vision of pediatric ureteroscope and control of fluoroscopy. Double J stent was placed after the operation in all cases. Stent was removed in another session, 8 weeks $(\mathrm{Group} A, \mathrm{n}=7)$ vs. 12 weeks (Group B, n=8) after endopyelotomy. Patients in both Groups were followed one, six and twelve months after the stent removal, and the anteroposterior renal pelvis diameter (APD), renal cortical thickness (CT) and degree of hydronephrosis (HDN) were recorded using the repeated measure test. P-value less than 0.05 were significant. We analyzed the data using SPSS software, version 20.

Results: The median interquartile range (IQR) age at time of surgery for group A and B were 24 (62) months and 12 (50) months respectively. Median (IQR) times between previous pyeloplasty and endopyelotomy were 6 (6) months and 12 (8.5) months in groups $\mathrm{A}$ and $\mathrm{B}$, respectively. The success rate of endopyelotomy after 12 months was $57.1 \%$ in group A and $87.5 \%$ in group B. The resolution of HDN was more prominent in the 12 week stenting group compared to the 8 week group during the 12 months follow-up period $(\mathrm{p}=0.030)$. The APD and CT in group B compared to group A was improved during follow-up period.

Conclusion: A higher one-year success rate of retrograde endopyelotomy in terms of improvements in the degree of HDN, APD and CT was observed when the double $\mathrm{j}$ stent was remained for 12-weeks rather than 8-weeks. This observation need to be validated in a large cohort study with a long term post procedural follow up.

Keywords: Double-J stent, Endopyelotomy, Treatment failure, Pyeloplasty, Ureteropelvic junction obstruction

Conflicts of Interest: None declared

Funding: None

*This work has been published under CC BY-NC-SA 1.0 license.

Copyright $\subseteq$ Iran University of Medical Sciences

Cite this article as: Shirazi M, Aminsharifi A, Ahmed F, Makarem A, Zahraei SA, Asmaarian N. The impact of post-procedural ureteric stent duration on the outcome of retrograde endopyelotomy for management of failed open pyeloplasty in children: a preliminary report. Med $J$ Islam Repub Iran. 2020 (25 Aug);34:105. https://doi.org/10.47176/mjiri.34.105

Introduction

Ureteropelvic junction obstruction (UPJO) is the most

Corresponding author: Dr Alireza Aminsharifi, ali.amin.sharifi@duke.edu

1. Department of Urology, Shiraz University of Medical Science, Shiraz, Iran

2. Division of Urology, Duke University Hospital, Durham, NC, USA

3. Urology Research Center, Althora General Hospital, Department of Urology, Ibb University of Medical Sciences, Ibb, Yemen

4. Student Research Committee, Shiraz University of Medical Science, Shiraz, Iran

5. Department of Biostatics, Shiraz University of Medical Science, Shiraz, Iran common cause of fetal hydronephrosis (HDN) (1), which

\section{$\uparrow$ What is "already known" in this topic:}

Retrograde endopyelotomy (RE) is considered as a minimally invasive modality for managing the failed pyeloplasty, thanks to its less morbidity. In the present study, we evaluate the outcome of RE and post-procedural stenting affect in managing failed open pyeloplasty in children.

$\rightarrow$ What this article adds:

Study indicate a higher one-year success rate of retrograde endopyelotomy in terms of improvements in the degree of HDN, APD and CT for management of the failed open pyeloplasty when the double $\mathrm{j}$ stent was placed for 12 weeks rather than 8 weeks after the procedure. 
may present with flank pain, nausea/vomiting, urinary infection, and renal stones (2). Spontaneous resolution of hydronephrosis (HDN) with a g ood outcome in terms of renal function can be observed in up to $87 \%$ of conservatively managed renal units (3). On the other hand, it has also been shown that in more than $50 \%$ of children with antenatal diagnosis of UPJO, surgical intervention (i.e. open pyeloplasty) may be required (4). While open pyeloplasty is generally a highly successful procedure, failed pyeloplasty (secondary UPJO) can be challenging (5). Current options to treat the failed pyeloplasty include endoscopic, open and laparoscopic procedures. Anatomical abnormalities, the child's age and clinical presentations are amongst the factors that usually determine the type of surgical approach (6).

Endopyelotomy is considered as a minimally invasive modality for managing the failed pyeloplasty. While both antegrade and retrograde approaches have been widely used, thanks to its less morbidity, retrograde endopyelotomy is a good option in this clinical scenario (6). On the contrary, some studies showed that open redo pyeloplasty are more successful than minimally invasive ones to treat failed pyeloplasty (7). In the present study, we evaluate the outcome of retrograde endopyelotomy in managing failed open pyeloplasty in children. We also report how the duration of post-procedural stenting may affect the endopyelotomy outcome.

\section{Methods}

In a retrospective cross-sectional study between20102015, all children (Fifteen) who were underwent retrograde endopyelotomy due to previous failed open pyeloplasty were enrolled in this study. We used patient records to collect information.Patients with renal failure and/or renal calculi were excluded. Written informed consent was obtained from the patient's parents or guardian before this study. The indications for retrograde endopyelotomy were febrile urinary tract infection (UTI), progressive HDN and/or increase in anteroposterior renal pelvis diameter (APD) measured on serial ultrasonographic evaluation after open pyeloplasty.

To assess the endopyelotomy outcome, the patients were evaluated with serial US to monitor the APD, renal cortical thickness (CT) and degree of HDN of the affected kidney.

\section{Surgical Technique- Retrograde Endopyelotomy}

All procedures were done under general anesthesia in lithotomy position by one pediatric urologist (MS). Under direct visualization by pediatric Cystoscope, a 0.035 -inch Zebra $^{\mathrm{TM}}$ guide wire (Boston Scientific, Watertown, MA, USA) was passed through the involved ureter as the safety guide wire. Then, ureteropyeloscopy was performed with 4.5Fr-pediatric semi-rigid ureteroscope (Richard Wolf GmBH, Knittlingen, Germany). The UPJ was visualized and evaluated under the direct vision of ureteroscope and under fluoroscopic guide after retrograde injection of the contrast material. A 3Fr ureteral catheter with its metallic stylet was used as monopolar electrocautery hook. Under direct vision of ureteroscope, the stenotic segment of the
UPJ was incised using 35-40 Watt electrocautery cutting mode. The incision was made on posterolateral aspect of the stenotic UPJ segment, deepened enough to the peripelvic fat. After ensuring a wide UPJ segment, double $\mathrm{J}$ stent (BIOTEQ CORP) was inserted in the ureter. We put one brand in all patients. Stent size varied from 3 to 4 Fr $16 \mathrm{~cm}$. and a Foley catheter was kept in place for 24 to $48 \mathrm{~h}$. The stent was then removed in another session 8 weeks (Group A) vs. 12 weeks (Group B) after the endopyelotomy.

\section{Study Outcome}

Before endopyelotomy, preoperative data such as age, the time between endopyelotomy and previous pyeloplasty, APD, renal CT, degree of HDN, and the indication for Endopyelotomy were collected. Patients in both Groups were followed one, six and twelve months after the stent removal. The APD, renal cortical thickness (CT) and degree of HDN were recorded. The degree of HDN was graded according to the Society for Fetal Urology system (8). Failure was defined as the need for another procedure due to progressive HDN or febrile UTI.

\section{Statistical analysis}

Normality of data was tested using KolmogorovSmirnov and Shapiro-Wilk test, when data are nonnormally distributed nonparametric test were used.

For comparison of quantitative data between the two Groups, Mann-Whitney $U$ test and for comparison of qualitative data Fisher's exact tests were used. To check the serial APD and CT the repeated measure test was used. Then Due to the existing limitations in our sample size, effect size (ES) measures were used to quantify the magnitude of clinically significant differences between the two Groups. The magnitude of effect size $<0.2,0.2-0.49$, $0.5-0.79$ and $>0.8$ were considered as negligible, small, moderate and large, respectively (9).

Data are presented as means and standard deviations, median and interquartile range and frequency and percentage, where appropriate. P-value less than 0.05 were considered as significant. We analyzed the data using SPSS software, version 20, Armonk, NY: IBM Corp.

\section{Results}

During the study period, we performed 470 pyeloplasties and fifteen patients underwent retrograde ureteroscopic endopyelotomy for their failed open pyeloplasty. These 15 patients categorized into two Groups according to their post-procedural stent duration as Group A: 8-week stenting ( $\mathrm{n}=7 ; 6$ males) and Group B: 12-week stenting $(\mathrm{n}=8 ; 5$ males).

Baseline and clinical characteristics of patients with failed open pyeloplasty who underwent retrograde endopyelotomy. All patients had double J stent after endopyelotomy, which was removed 8 weeks (Group A) vs. 12 weeks (Group B) after the procedure (Table 1).

The patients' median (IQR) age at the time of surgery for Groups A and B 24 (62) months and 12 (50) months old, respectively. The left side was involved in $5(71.4 \%)$ cases in Group A and in 4 (50\%) cases in Group B. Medi- 
Table 1. Baseline and clinical characteristics of patients with failed open pyeloplasty who underwent retrograde endopyelotomy. All patients had double J stent after endopyelotomy, which was removed 8 weeks (Group A) vs. 12 weeks (Group B) after the procedure.

\begin{tabular}{|c|c|c|c|c|c|c|}
\hline & $\begin{array}{l}\text { Patient } \\
\text { no. }\end{array}$ & Sex & $\begin{array}{c}\text { Age at retrograde } \\
\text { endopyelotomy (month) }\end{array}$ & $\begin{array}{l}\text { Time to failure after } \\
\text { Pyeloplasty (month) }\end{array}$ & $\mathrm{L} / \mathrm{R}$ & $\begin{array}{l}\text { Anatomical and functional status of the affected } \\
\text { kidney before endopyelotomy* }\end{array}$ \\
\hline \multirow{8}{*}{ Group A } & 1 & $\mathrm{M}$ & 72 & 6 & $\mathrm{~L}$ & RF: Moderate, APD:70mm, CT:5mm \\
\hline & 2 & M & 10 & 8 & $\mathrm{R}$ & RF: Good, APD:50 mm, CT:8mm \\
\hline & 3 & M & 9 & 6 & $\mathrm{R}$ & RF: Good, APD:37mm, CT:5mm \\
\hline & 4 & M & 51 & 20 & $\mathrm{~L}$ & RF: Good, ADP:37mm, CT: $14 \mathrm{~mm}$ \\
\hline & 5 & M & 24 & 6 & $\mathrm{~L}$ & RF: Poor, APD:80mm, CT:3mm \\
\hline & 6 & $\mathrm{~F}$ & 144 & 3 & $\mathrm{~L}$ & RF: Moderate, APD:70mm, CT:5mm \\
\hline & 7 & M & 24 & 12 & $\mathrm{~L}$ & RF: Good, APD:40mm, CT:3mm \\
\hline & 8 & $\mathrm{~F}$ & 18 & 13 & $\mathrm{R}$ & RF: Moderate, APD:40mm, CT: $2.5 \mathrm{~mm}$ \\
\hline \multirow{7}{*}{ Group B } & 9 & M & 108 & 12 & $\mathrm{~L}$ & RF: Good, APD:48mm, CT: $8 \mathrm{~mm}$ \\
\hline & 10 & $\mathrm{~F}$ & 60 & 8 & $\mathrm{R}$ & RF: Moderate, APD: $45 \mathrm{~mm}, \mathrm{CT}: 8 \mathrm{~mm}$ \\
\hline & 11 & M & 72 & 6 & $\mathrm{~L}$ & RF: Poor, APD:97mm, CT:6mm \\
\hline & 12 & $\mathrm{~F}$ & 42 & 19 & $\mathrm{R}$ & RF: Good, APD:30mm, CT:3mm \\
\hline & 13 & M & 78 & 12 & $\mathrm{~L}$ & RF: Good, APD:50mm, CT:8mm \\
\hline & 14 & M & 48 & 27 & $\mathrm{~L}$ & RF: Moderated, APD:38 mm, CT:5mm \\
\hline & 15 & M & 21 & 12 & $\mathrm{R}$ & RF: Moderate, APD:52 mm, CT:8mm \\
\hline
\end{tabular}

Abbreviation: APD: anterior posterior renal pelvis diameter, CT: Cortical thickness L/R: Left/Right; M/F: Male/Female; RF: renal function

* Split Renal function (RF) was assessed using diethylenetriaminepentaacetic acid (DTPA) and was categorized as: good (more than 40\%), moderate (40-25\%) and poor (less than $25 \%$ ). The APD and CT were assessed by ultrasonographic evaluation.

an (IQR) time between previous pyeloplasty and endopyelotomy was 6 (6) months and 12 (8.5) months in Group A and B, respectively. Preoperative US showed severe HDN and the renogram curve was obstructive in all the patients. Indications for surgery were worsening HDN with parenchymal thinning among 4 patients $(57.1 \%)$ in Group A and 6 patients (75\%) in Group B, and recurrent febrile UTI among 3 patients (42.9\%) in Group A and 2 patients $(25 \%)$ in Group B. Retrograde endopyelotomy was uneventful in all patients and they were discharged on the first post-operative day.

Mean APD was improved in the 12-week stenting Group compared to the 8- week Group during the 12 month follow-up $(25.5 \pm 10.25 \mathrm{~mm}$ vs. $40.6 \pm 17.05 \mathrm{~mm})$ although this difference was not statistically significant $(p=0.078)$. The estimated Cohen's d effect size of APD in the $6^{\text {th }}$ and $12^{\text {th }}$ months following stent removal was clinically important (ES: 0.66, 1.07).

There was a trend toward a thicker CT of the involved kidney 6 months after the stent removal in Group B versus in Group A (8.37 $\pm 3.11 \mathrm{~mm}$ vs. $5.71 \pm 2.56 \mathrm{~mm}, \mathrm{p}=0.05)$.
The same pattern was documented 12 months after the stent removal $(8.62 \pm 2.92 \mathrm{~mm}$ vs. $5.40 \pm 1.34 \mathrm{~mm}$, $\mathrm{p}=0.050)$. The estimated Cohen's d effect size of CT in the $1 \mathrm{st}, 6^{\text {th }}$ and $12^{\text {th }}$ months following stent removal was moderate and large, which were clinically important (ES: $0.62,0.93,1.41)$. The degree of HDN was significantly improved in the 12 weeks stenting Group compared to the 8 week Group after 12 months of follow-up $(p=0.030)$.

One month after the stent removal, we found a reduction in HDN degree in 3 cases (42.9\%) in Group A and 7 cases $(87.5 \%)$ in Group B. No change in HDN severity was noted in other children. After the six month follow up period, we found a reduction of HDN in 5 cases $(71.4 \%)$ in Group A and all the cases in Group B. After 12 months of follow up, no change was observed in the HDN degree in 4 cases $(57.1 \%)$ in Group A and 2 cases (25\%) in Group B.

Changes in the degree of hydronephrosis (HDN) during the follow-up Ultrasonographic evaluation after the stent removal following retrograde endopyelotomy. Patients in Group A had 8- week and those in Group B had 12-week stenting after endopyelotomy. In brief, at all check points

Table 2. Changes in the degree of hydronephrosis (HDN) during the follow-up ultrasonographic evaluation after the stent removal following retrograde endopyelotomy. Patients in Group A had 8- week and those in Group B had 12-week stenting after endopyelotomy.

\begin{tabular}{|c|c|c|c|c|c|c|}
\hline & Patient no & 1 month & 6 month & 12 month & Endopyelotomy outcome & Complications \\
\hline \multirow{7}{*}{ Group A } & 1 & $\mathrm{HDN}^{*}:+++$ & HDN: +++ & & Failure at 6 months & \multirow{3}{*}{ Stent migration } \\
\hline & 2 & HDN:++ & HDN: ++ & HDN: ++ & Successful & \\
\hline & 3 & HDN:++ & HDN:++ & HDN: ++ & Successful & \\
\hline & 4 & HDN:++ & HDN: +++ & & Failure at 9 months & \multirow{12}{*}{ Stent encrustation } \\
\hline & 5 & HDN:+++ & HDN:++ & HDN:+++ & Failure at 12 months & \\
\hline & 6 & HDN: +++ & HDN: ++ & HDN:++ & Successful & \\
\hline & 7 & HDN: +++ & HDN: ++ & HDN:++ & Successful & \\
\hline \multirow{8}{*}{ Group B } & 8 & HDN:++ & HDN:++ & HDN:+ & Successful & \\
\hline & 9 & HDN:++ & HDN: ++ & HDN:++ & Failure at 12 months & \\
\hline & 10 & HDN:++ & HDN: + & HDN: + & Successful & \\
\hline & 11 & HDN: +++ & HDN: ++ & HDN: ++ & Successful & \\
\hline & 12 & HDN:++ & HDN: ++ & HDN:+ & Successful & \\
\hline & 13 & HDN: ++ & HDN: ++ & HDN:+ & Successful & \\
\hline & 14 & HDN:++ & HDN:+ & HDN: + & Successful & \\
\hline & 15 & HDN: ++ & HDN: + & HDN: + & Successful & \\
\hline
\end{tabular}

*+: mild HDN (grade I or II), ++: moderate HDN (grade III), +++: severe HDN (grade IV). 
there was a trend toward a less severe HDN in Group B compared to Group A (Table 2).

The success rate after 12 months was $57.1 \%$ in Group A and $87.5 \%$ in Group B. Endopyelotomy failed to relieve the obstruction in 3 patients $(42.9 \%)$ in Group A and one patient (12.5\%) in Group B. Post-operative complications consisted of migration of double $\mathrm{j}$ stent, which required repositioning in one patient $(14.3 \%)$ in Group $\mathrm{A}$ and double $\mathrm{j}$ stent encrustation in one patient $(12.5 \%)$ in Group B, which was treated successfully by transureteral lithotripsy. Group A failures were detected during 6, 9 and 12 month investigations, while in Group B, the only failure was detected in 12 month- follow-up US.

The pattern of anterior posterior diameter (APD) changes on ultrasongraphic (US) evaluation in the 1st, 6th and $12^{\text {th }}$ months after stent removal in Group A versus Group B. In contrast to group A, the APD in group B is consistently improved during the follow-up period.

The pattern of cortical thickness of the ipsilateral kidney on ultrasongraphic evaluation in the $1 \mathrm{st}$, 6th and $12^{\text {th }}$ months after stent removal in Group A versus Group B. In contrast to group A, the cortical thickness in group B consistently improved during follow-up period.

All endopyelotomy failures were managed with salvage open pyeloplasty.

\section{Discussion}

Recurrent Ureteropelvic junction obstruction is a relatively uncommon complication after dismembered pyeloplasty. Postoperative fibrosis and scaring at the site of anastomosis are the main causes of pyeloplasty failure (10). Current options to treat the failed pyeloplasty include endoscopic modalities (balloon dilation, antegrade and retrograde endopyelotomy), open pyeloplasty and laparoscopic repair (11). Retrograde endopyelotomy has been shown as a suitable option for management of secondary UPJO with a success rate up to $91 \%$ (11). Repeated open surgical repair for failed pyeloplasty can be associated with significant surgical complications, such as substantial urinary extravasations (up to 10\%), and nephrectomy (up to $33-66 \%)(7,12)$. As a minimally invasive option, laparoscopic redo pyeloplasty can also be challenging due to significant amount of fibrosis amount the renal pelvis and proximal ureter, making dissection and anastomosis cumbersome (13).

We performed endopyelotomy using electrocautery with low-power electrical cutting current. The use of lowenergy electrocautery for incising the fibrotic UPJ has been previously shown to be effective with a success rate of $70 \%$ after a mean follow-up period of 20 months. Lowenergy profile in this procedure would be associated with minimal scattering and damaging to the healthy ureteral wall (14). After primary pyeloplasty, Veenboer et al. believe that the risk for significant complications related to the injury of the crossing vessels during secondary endopyelotomy is limited. However, secondary obstruction caused by the vessel should not be underestimated and we did not assessed this prior to procedure (14).

In our study, different times of failure has been shown in Group A versus Group B. Failures tended to occur ear- lier when the double $\mathrm{j}$ stent was dwelled 8 weeks (Group A) versus 12 weeks (Group B).We managed all endopyelotomy failures with salvage open pyeloplasty as recommended by Patel et al. (15). Potential benefits of stenting after endopyelotomy include maximum urinary diversion, anastomosis alignment during the healing period, decreased rate of extravasations, and potentially shorter hospital stay (16). To the best of our knowledge, this is the first report of comparing the effect of 8-week versus 12-week stenting on the outcome of endopyelotomy. There is no consensus about the duration of stenting after endopyelotomy and its possible effect on the outcome. Previous experimental studies showed a complete circumferential smooth muscular regeneration of the ureter after 12 weeks, confirmed by immunohistochemistry studies and electron microscopy (17). In previous studies, the double $\mathrm{j}$ stenting duration after endoscopic procedure was varied between 4-12 week (18-20). We showed that a 12week post-procedural stenting might be associated with a better outcome; however, only a long-term prospective study can appropriately address this issue. During the stenting period, in both groups, we had complications such as double $\mathrm{j}$ stent malposition or encrustation which were managed by ureteroscopy.

For evaluation of post-operative outcome after management of UPJO, in general, two modalities (i.e. Diuretic renogram versus US) are used. While diuretic renogram is the gold standard modality, its invasive nature (compared to US), poor anatomic delineation, as well as its high cost are limiting factors for its widespread use (21). On the other hand, variables such as APD, CT and degree of HDN are surrogate markers of drainage improvement after the management of UPJO when US is used during the follow up period (22). Previous studies documented the improvement of HDN and CT in the follow-up ultrasonographic evaluation after pyeloplasty $(23,24)$. In the present study, all patients were followed after endopyelotomy with US, and diuretic renogram was used selectively in symptomatic patients and/or in those with adverse US findings.

One of the limitations of this study was the sample size of our study that is admittedly too small to run any powerful statically analysis. However, we used effect size measurement to address this limitation. Therefore, this is just an observational report which requires validation with a large sample size with randomized criteria.another limitation of this study was luck of serum and urine factors in following the patients. Another limitation was the lower time between failed pyeloplasty and endopyelotomy in Group A. Moreover, the effect of post-endopyelotomy stent duration on the procedural outcome may be time dependent and requires to be investigated in long-term studies.

\section{Conclusion}

In this study, we observed a higher one-year success rate of retrograde endopyelotomy in terms of improvements in the degree of HDN, APD and CT for management of the failed open pyeloplasty when the double $\mathrm{j}$ stent was placed for 12 weeks rather than 8 weeks after 
the procedure. Retrograde endopyelotomy failures tended to occur earlier in 8 week- versus 12 week- postprocedural stenting Group. Whether these improved outcomes persist during long-term follow-ups require further studies.

\section{Acknowledgements}

The authors would like to thank Shiraz University of Medical Sciences, Shiraz, Iran and also Center for Development of Clinical Research of Nemazee Hospital and Dr. Nasrin Shokrpour for editorial assistance.

\section{Ethical statement}

This study was approved by the ethics committee of Shiraz University of Medical Sciences with the ID: 93-0101-16910. Written informed consent was obtained from the patient's parents or guardian before the operation.

\section{Conflict of Interests}

The authors declare that they have no competing interests.

\section{References}

1. Swords KA, Peters CA. Neonatal and early infancy management of prenatally detected hydronephrosis. Arch Dis Child Educ Pract Ed. 2015;100:F460-F4.

2. Dias CS, Silva JMP, Pereira AK, Marino VS, Silva LA, Coelho AM, et al. Diagnostic accuracy of renal pelvic dilatation for detecting surgically managed ureteropelvic junction obstruction. J Urol. 2013;190:661-6.

3. Karnak I, Woo LL, Shah SN, Sirajuddin A, Ross JH. Results of a practical protocol for management of prenatally detected hydronephrosis due to ureteropelvic junction obstruction. Pediatr Surg Int. 2009:25:61-7.

4. Chertin B, Pollack A, Koulikov D, Rabinowitz R, Hain D, HadasHalpren I, et al. Conservative treatment of ureteropelvic junction obstruction in children with antenatal diagnosis of hydronephrosis: lessons learned after 16 years of follow-up. Eur Urol. 2006;49:734-8.

5. Asensio M, Gander R, Royo GF, Lloret J. Failed pyeloplasty in children: is robot-assisted laparoscopic reoperative repair feasible? J Pediatr Urol. 2015;11:69. e1-. e6.

6. Weitz M, Portz S, Laube GF, Meerpohl JJ, Bassler D. Surgery versus non-surgical management for unilateral ureteric-pelvic junction obstruction in newborns and infants less than two years of age. Cochrane Database Syst Rev. 2016.

7. Canning DA. Re: Failed Pyeloplasty in Children: Revisiting the Unknown. J Urol. 2014;192:542-3.

8. Fernbach S, Maizels M, Conway J. Ultrasound grading of hydronephrosis: introduction to the system used by the Society for Fetal Urology. Pediatr Radiol. 1993;23:478-80.

9. Cohen J. Statistical power analysis for the behavioral sciences $2 \mathrm{nd}$ edn. Erlbaum Associates, Hillsdale; 1988

10. Nagdeve NG, Bhingare PD, Sarawade P. A randomized control trial comparing outcome after stented and nonstented Anderson-Hynes dismembered pyeloplasty. J Indian Assoc Pediatr Surg. 2018;23:186.

11. Samarasekera D, Chew BH. Endopyelotomy still has an important role in the management of ureteropelvic junction obstruction. Can Urol Assoc J. 2011;5:134.

12. Kelalis PP, Culp OS, Stickler GB, Burke EC. Ureteropelyic Obstruction in Children: Experiences with 109 Cases. J Urol. 1971;106:418-22.

13. Chiancone F, Fedelini M, Pucci L, Meccariello C, Fedelini P. Laparoscopic management of recurrent ureteropelvic junction obstruction following pyeloplasty: a single surgical team experience with 38 cases. Int Braz J Urol. 2017;43:512-7.

14. Veenboer PW, Chrzan R, Dik P, Klijn AJ, de Jong TP. Secondary endoscopic pyelotomy in children with failed pyeloplasty. Urology. 2011;77:1450-4.
15. Patel T, Kellner CP, Katsumi H, Gupta M. Efficacy of endopyelotomy in patients with secondary ureteropelvic junction obstruction. J Endourol. 2011;25:587-91.

16. Smith KE, Holmes N, Lieb JI, Mandell J, Baskin LS, Kogan BA. Stented versus nonstented pediatric pyeloplasty: a modern series and review of the literature. J Urol. 2002;168:1127-30.

17. Rehman J, Ragab MM, Venkatesh R, Sundaram CP, Ali Khan S, Sukkarieh T, et al. Smooth-muscle regeneration after electrosurgical endopyelotomy in a porcine model as confirmed by electron microscopy. J Endourol. 2004;18:982-8.

18. Braga LH, Lorenzo AJ, Skeldon S, Dave S, Bagli DJ, Khoury AE, et al. Failed pyeloplasty in children: comparative analysis of retrograde endopyelotomy versus redo pyeloplasty. J Urol. 2007:178:2571-5

19. Thomas J, DeMarco R, Donohoe J, Adams M, POPE IV J, BROCK III J. Management of the failed pyeloplasty: a contemporary review. J Urol. 2005;174:2363-6.

20. Kavoussi L, Meretyk S, Dierks S, Bigg S, Gup D, Manley C, et al. Endopyelotomy for secondary ureteropelvic junction obstruction in children. J Urol. 1991;145:345-9.

21. Carpenter CP, Tolley E, Tourville E, Sharadin C, Giel DW, Gleason JM. Hydronephrosis After Pyeloplasty:"Will It Go Away?". Urology. 2018;121:158-163.

22. Chipde SS, Lal H, Gambhir S, Kumar J, Srivastava A, Kapoor R, et al. Factors predicting improvement of renal function after pyeloplasty in pediatric patients: a prospective study. J Urol. 2012;188:262-5.

23. Tapia J, Gonzalez R. Pyeloplasty improves renal function and somatic growth in children with ureteropelvic junction obstruction. J Urol. 1995;154:218-22.

24. Kis E, Verebély T, Kövi R, Máttyus I. The role of ultrasound in the follow-up of postoperative changes after pyeloplasty. Pediatr Radiol. 1998;28:247-9. 